\section{International Scientific Journal Theoretical \& Applied Science}

\author{
p-ISSN: 2308-4944 (print) e-ISSN: 2409-0085 (online) \\ Year: 2017 Issue: 04 Volume: 48
}

Published: 10.04.2017 http://T-Science.org

SECTION 2. Applied mathematics. Mathematical modeling.
Mahruy Saidalieva

Dr, Head of dept. "Regulatorika"

Centre for the development of software and hardware program complexes at Tashkent University of Informational Technologies, Tashkent, Uzbekistan regulatorika@yahoo.com

Mohiniso Bahromovna Hidirova $\mathrm{PhD}$, Senior Scientist, dept. "Regulatorika" Centre for the development of software and hardware program complexes at Tashkent Univesity of Informational Technologies, Tashkent, Uzbekistan regulatorika@yahoo.com

\title{
MATHEMATICAL MODELING REGULATORY MECHANISMS OF HEPATITIS B VIRUSES'S MICRO-RNA ACTION
}

Abstract: This paper considers the method for modeling regulatorika of the interconnected activity between molecular-genetic systems of hepatocytes and hepatitis B viruses (HBV). During computing experiments with the developed program complex it is established that there are the following regimes of the process, which depend on $H B V$ miRNA concentration: clarification, symbiosis, regular and irregular fluctuations, sharp destructive changes which define various clinical forms of disease.

Key words: modeling, regulatorika, functional-differential equations with delay, miRNA, viral hepatitis, functional equation.

Language: Russian

Citation: Saidalieva M, Hidirova MB (2017) MATHEMATICAL MODELING REGULATORY MECHANISMS OF HEPATITIS B VIRUSES'S MICRO-RNA ACTION. ISJ Theoretical \& Applied Science, 04 (48): 19-23.

Soi: http://s-o-i.org/1.1/TAS-04-48-4 Doi: crossef https://dx.doi.org/10.15863/TAS.2017.04.48.4

\section{УДК 576.35:517.948}

\section{МАТЕМАТИЧЕСКОЕ МОДЕЛИРОВАНИЕ РЕГУЛЯТОРИКИ МИКРО-РНК ВИРУСОВ ГЕПАТИТА В}

Аннотация: В статье рассматривается метод моделирования регуляторики взаимосвязанной деятельности молекулярно-генетических систем гепатоциттов и вирусов гепатита В. Выявлены, в ходе вычислительных экспериментов с разработанным программным комплексом на основе предложенных уравнений, следующие режимы рассматриваемого процесса, которые зависят от концентрации микроРНК вирусов гепатита В: очищение, симбиоз, регулярные и нерегулярные колебания, резкие деструктивные изменения.

Ключевые слова: моделирование, регуляторика, функичонально-дифференцииальные уравнения с запаздыванием, микроРНК, вирусные гепатиты, функциональные уравнения.

\section{Введение}

Инфицирование вирусами гепатита В (HBV) остается глобальной проблемой здравоохранения. Иногда следствием хронической $\mathrm{HBV}$-инфекции бывает первичноклеточный рак печени. HBV модифицирует клеточный эпигеном. Геном вирусов гепатита В кодирует микроРНК (miRNA). В последние годы наблюдается бурный рост работ по генной регуляции, связанный с открытием в геноме человека генов, кодирующих регуляторные молекулы микроРНК, которые негативно регулируют экспрессию многих генов [1-11]. МикроРНК синтезируются из более длинных предшественников и не кодирует белки [1-2]. В большинстве случаев miRNA действуют как репрессоры трансляции за счет связывания с иРНК. МикроРНК вирусов гепатита В не транслируют белки, но являются регуляторами синтеза белка. Одна и та же микроРНК вирусной генетической системы нелинейным, сложным образом регулирует трансляцию многих и-РНК генетической системы гепатоцита (рисунок 1). МикроРНК приводят к разрушению и-РНК или подавлению трансляции с таргетной и-РНК. При этом они способны подавлять трансляцию 
посредством различных механизмов: как на этапе инициации, так и в процессе элонгации. Механизм прекращения трансляции также зависит от степени комплементарности связывающихся областей микроРНК и и-РНК. Деградация и-РНК включает такие процессы, как деаденилирование, декапирование и экзонуклеарное расщепление молекулы и-РНК. Однако, до конца механизм действия микроРНК еще не изучен. Раскрытие регуляторных механизмов действия микроРНК существенно поможет определению механизмов формирования и развития инфекционного процесса при вирусном гепатите В на молекулярно-генетическом уровне и позволит найти эффективные пути целенаправленного лечебного и профилактического воздействия на молекулярно-генетическую систему гепатоцита. Обзор работ показывает, что на сегодняшний день отсутствуют работы по математическому моделированию регуляторных механизмов действия микроРНК с учетом временных взаимоотношений, кооперативных процессов и комбинированных обратных связей.

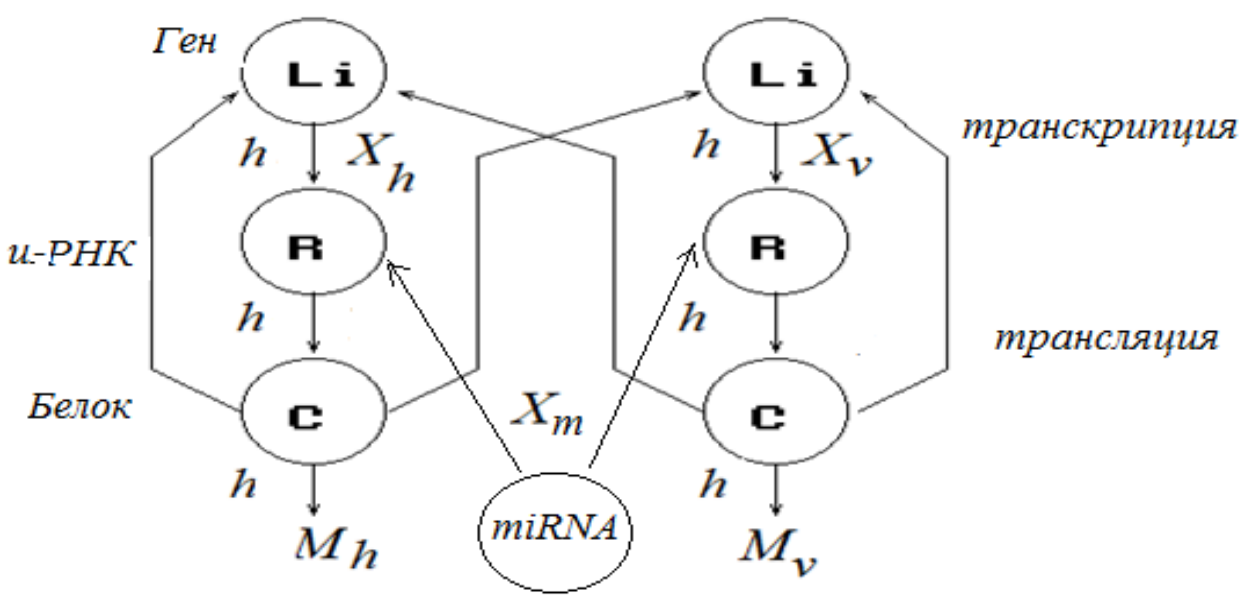

Рисунок 1 - Схема взаимосвязанной деятельности молекулярно-генетических систем гепатоцитов и вирусов гепатита В с учетом действия микроРНК.

\section{Материалы и методы}

Вирусные микроРНК могут участвовать в подавлении экспрессии собственных вирусных генов. Активность молекулярно-генетической системы вирусов гепатита В зависит от уровня функционирования таковой гепатоцита. С учетом этих факторов регуляторика взаимосвязанной деятельности молекулярно-генетических систем гепатоцита и вирусов гепатита В может быть количественно описана следующей системой функционально-дифференциальных уравнений, построенной с использованием метода математического моделирования регуляторики живых систем [12]

$$
\begin{aligned}
& \frac{d X_{h}(t)}{d t}=\gamma_{h} X_{h}(t-h) e^{-\delta_{h} M_{h}(t-h)-m X_{m}(t-h)}-b_{h} X_{h}(t) \\
& \frac{d X_{v}(t)}{d t}=\gamma_{v} X_{h}(t-h) X_{v}(t-h) e^{-\delta_{h} M_{h}(t-h)-\delta_{v} M_{v}(t-h)}- \\
& -b_{v} X_{v}(t)
\end{aligned}
$$

$$
\begin{aligned}
& \frac{d X_{m}(t)}{d t}=\gamma_{v} X_{h}(t-h) X_{v}(t-h) X_{m}(t-h) e^{-m X_{m}(t-h)}- \\
& -b_{m} X_{m}(t) ; \\
& \frac{d M_{h}(t)}{d t}=\mu_{h} X_{h}(t-h)-c_{h} M_{h}(t) ; \\
& \frac{d M_{v}(t)}{d t}=\mu_{v} X_{v}(t-h)-c_{v} M_{v}(t) ; \\
& X_{m}(t)=\varphi_{m}(t) ; \quad X_{h}(t)=\varphi_{h}(t) ; \quad X_{v}(t)==\varphi_{v}(t) ; \\
& M_{h}(t)=\eta_{h}(t) ; \quad M_{v}(t)==\eta_{v}(t) \\
& \quad n p u \quad t_{0}-h \leq t \leq t_{0} \quad\left(t_{0}>h\right)
\end{aligned}
$$

где $\varphi_{m}(t), \varphi_{h}(t), \varphi_{v}(t), \eta_{h}(t), \eta_{v}(t)$ - непрерывные функции на $\left[t_{0}-h, t_{0}\right]$; $t_{0}-$ начало модельных исследований (при аналитических исследованиях, в случае необходимости, можно принять $t_{0}=0$ ); $X_{h}(t)$ выражает концентрацию и-РНК генетической системы гепатоцита; $X_{v}(t)$ 


\begin{tabular}{|c|c|c|c|c|c|c|}
\hline Impact Factor: & $\begin{array}{l}\text { ISRA (India) } \\
\text { ISI (Dubai, UAF } \\
\text { GIF (Australia) } \\
\text { JIF }\end{array}$ & $\begin{array}{l}=1.344 \\
=0.829 \\
=0.564 \\
=1.500\end{array}$ & $\begin{array}{l}\text { SIS (USA) } \\
\text { PИНЦ (Russia) } \\
\text { ESJI (KZ) } \\
\text { SJIF (Morocco) }\end{array}$ & $\begin{array}{l}=0.912 \\
=0.234 \\
=3.860 \\
=\mathbf{2 . 0 3 1}\end{array}$ & $\begin{array}{l}\text { ICV (Poland) } \\
\text { PIF (India) } \\
\text { IBI (India) }\end{array}$ & $\begin{array}{l}=6.630 \\
=1.940 \\
=4.260\end{array}$ \\
\hline
\end{tabular}

выражает уровень активности системы транскрипции генетической системы вируса гепатита; $X_{m}(t)$ выражает концентрацию микроРНК генетической системы вирусов гепатита $\mathrm{B} ; M_{h}(t), M_{v}(t)$ - уровни активностей систем трансляции гепатоцита и вирусов гепатита В (концентрации белковых продуктов). Bсе параметры неотрицательны. В первых трех уравнениях системы (1) учитывается репрессорное влияние молекулярно-генетической системы вирусов гепатита В на функционирование гепатоцитов. Из системы уравнений (1) видно, что генетическая система гепатоцита может функционировать самостоятельно и отсутствие вирусов гепатита В $\left(M_{v}(t)=0\right)$ освобождает его от репрессивного экспоненциального члена в правой части первого уравнения. В отличие от этого, генетическая система вирусов гепатита В не может функционировать самостоятельно и «погибает» если молекулярно-генетическая система гепатоцита перестает функционировать $\left(M_{h}(t)=\right.$ $0)$. Учитывая, что вирусы гепатита В своими микроРНК воздействует на клетку печени, подавляя её, и затем беспрепятственно размножается, в качестве уравнений минимальной математической модели регуляторики молекулярно-генетической системы гепатоцита и вирусной микроРНК можно принять уравнения

$\delta_{1} \frac{d X(t)}{d t}=a X(t-1) e^{-\omega(t)}-X(t) ;$

$\delta_{2} \frac{d Y(t)}{d t}=b X(t-1) Y(t-1) e^{-\omega(t)}-Y(t)$

$\delta_{3} \frac{d Z(t)}{d t}=c X(t-1) Y(t-1) Z(t-1) e^{-\omega(t)}-Z(t)$,

$$
\omega(t)=X(t-1)+Y(t-1)+Z(t-1)
$$

где $X(t), Y(t), Z(t)$ - величины, характеризующие количество продуктов соответствующих генетических систем гепатоцита, вирусов гепатита В и концентрации микро-РНК вирусов гепатита В в момент времени $t ; \delta_{1}, \delta_{2}, \delta_{3}-$ параметры регуляторики системы; $a, b, c-$ параметры, характеризующие уровни активностей молекулярно-генетических систем гепатоцита, вирусов гепатита В и микро-РНК вирусов гепатита B; все параметры неотрицательны.

Качественное исследование функциональнодифференциальных уравнений регуляторики системы «гепатоцит-вирусы гепатита В» [12] привело к следующим условиям критического уровня концентрации микро-РНК (рисунок 2)

$$
a>1, \quad b>e, \quad c>e^{2} \text {. }
$$

Это приводит к следующим координатам нетривиального положения равновесия

$$
\begin{gathered}
\xi=1 ; \quad \eta=\frac{a}{c} ; \\
\mu=\ln a-1-\frac{a}{c} .
\end{gathered}
$$

Определение области изменения значений параметров из условия положительности данных координат (условие заражения) приводит к $a>e$ и соотношению $c=a /(\ln a-1)$.

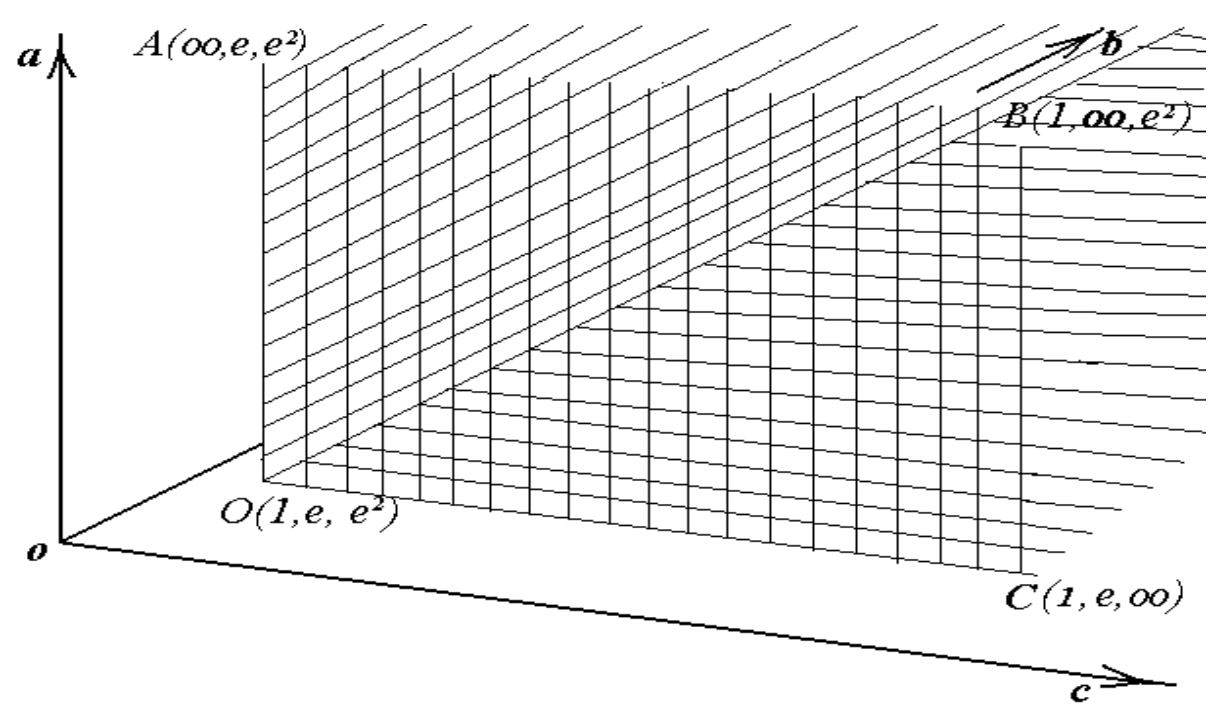

Рисунок 2 - Область изменения значений параметров уравнений (2) при критической концентрации микро-РНК. 


\begin{tabular}{|c|c|c|c|c|c|c|}
\hline Impact Factor: & $\begin{array}{l}\text { ISRA (India) } \\
\text { ISI (Dubai, UAE } \\
\text { GIF (Australia) } \\
\text { JIF }\end{array}$ & $\begin{array}{r}=1.344 \\
=0.829 \\
=0.564 \\
=1.500\end{array}$ & $\begin{array}{l}\text { SIS (USA) } \\
\text { PИНЦ (Russia) } \\
\text { ESJI (KZ) } \\
\text { SJIF (Morocco) }\end{array}$ & $\begin{array}{l}=0.912 \\
=0.234 \\
=\mathbf{3 . 8 6 0} \\
=\mathbf{2 . 0 3 1}\end{array}$ & $\begin{array}{l}\text { ICV (Poland) } \\
\text { PIF (India) } \\
\text { IBI (India) }\end{array}$ & $\begin{array}{l}=6.630 \\
=1.940 \\
=4.260\end{array}$ \\
\hline
\end{tabular}

Результаты качественного анализа показывают, что наличие в гепатоците инфекционного процесса гепатита В приводит к резкому увеличению активности молекулярногенетической системы гепатоцита. Результаты фрактального анализа с использованием значений энтропии Колмогорова (вычисления проводились на РС для отдельных уравнений (2) с дискретной модельной системой) показали возможность сложных колебаний при определенных значениях параметров. Исследование решений дискретных модельных уравнений системы (2), проведенное на РС с помощью построения диаграмм Ламерея (рисунки 3 и 4), вычисления ляпуновской величины, хаусдорфовой и высших размерностей, позволяет выявлять динамические характеристики поведения решений рассматриваемого уравнения, определять значения параметров наступления конкретных режимов и приближение границ областей однородных режимов поведения.

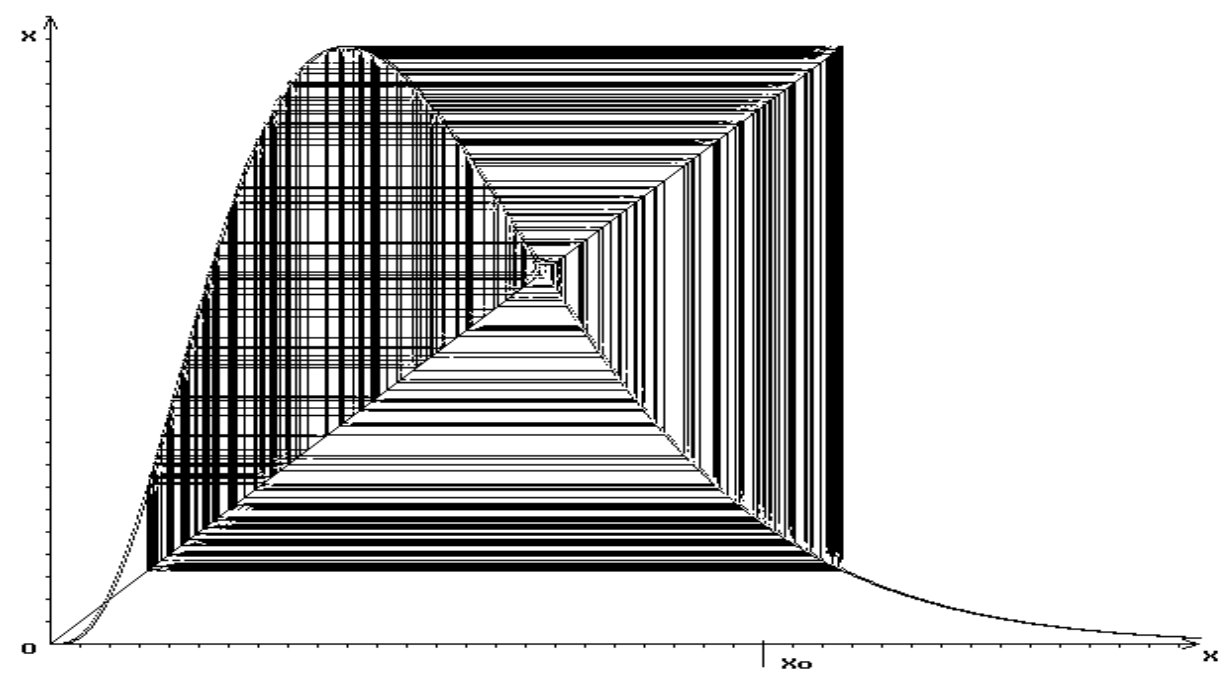

Рисунок 3 - Диаграмма Ламерея модельной системы (2) в области хаоса.

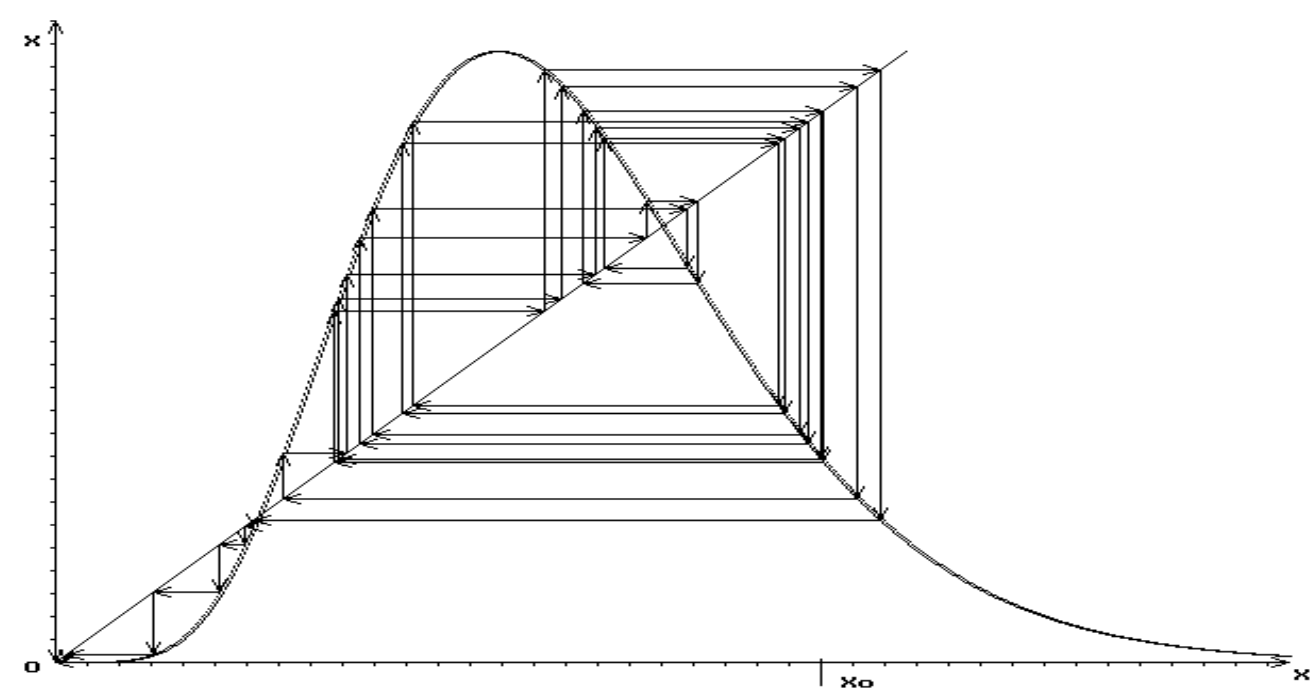

Рисунок 4 - Диаграмма Ламерея модельной системы (2), попавшей в сферу притяжения «черной дыры». 


\begin{tabular}{|c|c|c|c|c|c|c|}
\hline Impact Factor: & $\begin{array}{l}\text { ISRA (India) } \\
\text { ISI (Dubai, UAF } \\
\text { GIF (Australia) } \\
\text { JIF }\end{array}$ & $\begin{array}{l}=1.344 \\
=0.829 \\
=0.564 \\
=1.500\end{array}$ & $\begin{array}{l}\text { SIS (USA) } \\
\text { PИНЦ (Russia) } \\
\text { ESJI (KZ) } \\
\text { SJIF (Morocco) }\end{array}$ & $\begin{array}{l}=0.912 \\
=0.234 \\
=3.860 \\
=\mathbf{2 . 0 3 1}\end{array}$ & $\begin{array}{l}\text { ICV (Poland) } \\
\text { PIF (India) } \\
\text { IBI (India) }\end{array}$ & $\begin{array}{l}=6.630 \\
=1.940 \\
=4.260\end{array}$ \\
\hline
\end{tabular}

\section{Заключение}

Таким образом, результаты проведенных исследований математической модели регуляторики транскрипции и трансляции в молекулярно-генетической системе гепатоцита и вирусов гепатита В на основе бифуркационного и фрактального анализов, построения их фазовых и параметрических портретов показывают возможность сложного поведения взаимосвязанной молекулярно-генетической системы гепатоцита и вирусов гепатита В, включая механизмы взаимного подавления их активности и симбиотического функционирования.

Выявлены, в ходе вычислительных экспериментов с разработанным программным комплексом, следующие режимы рассматриваемого процесса (которые зависят от концентрации микроРНК вирусов гепатита В): очищение, симбиоз, регулярные и нерегулярные колебания, резкие деструктивные изменения, которые определяют различные клинические формы заболевания вирусным гепатитом В.

Общий анализ уравнений (1), (2) и серия вычислительных экспериментов позволили выяснить, что непосредственное влияние функционирования молекулярно-генетической системы вирусов гепатита В на гепатоцит осуществляется на основе механизма ингибирования. Подавление функционирования молекулярно-генетической системы гепатоцита прямо пропорционально уровню активности молекулярно-генетической системы вирусов гепатита В (в частности, уровню концентрации микроРНК). Причем подавление носит экспоненциальный характер. Это означает, что усиление подавления происходит не в линейном и не в кратном, а в степенном порядке. Видимо, этим механизмом определяется часто наблюдаемое превосходство молекулярногенетической системы вирусов при взаимном функционировании.

\section{References:}

1. Yates LA, Norbury CJ, Gilbert RJ (2013) The long and short of microRNA. Cell 2013;153: 516-519.

2. Pan F, Mao H, Deng L (2014) Prognostic and clinicopathological significance of microRNA21 overexpression in breast cancer: a metaanalysis. Int J Clin Exp Pathol 2014; $15 ; 7$ (9): 5622-5633

3. Hwang HW, Mendell JT (2007) MicroRNAs in cell proliferation, cell death, and tumorigenesis. Br J Cancer 2007;96:R40-44.

4. Zhenqiang W, Qiang C, Zhaoyan J (2014) Prognostic Role of MicroRNA-21 in Gastric Cancer: a Meta-Analysis. Med Sci Monit 2014; 18 (20): 1668-1674.

5. Li C, Gao Y, Zhang K, Chen J, Han S, Feng B, Wang R, Chen L (2015) Multiple Roles of MicroRNA-100 in Human Cancer and its Therapeutic Potential. Cell Physiol Biochem 2015;37: 2143-2159.

6. Su S, Cao W, Liu W, Lu Z, Zhu D, Chao J, Weng L, Wang L, Fan C, Wang L (2017) Dualmode electrochemical analysis of microRNA21 using gold nanoparticle-decorated $\operatorname{MoS}(2)$ nanosheet. Biosens Bioelectron. 2017, pp. 552559.
7. Zhao C, Ma ZG, Mou SL, Yang YX, Zhang YH, Yao WC (2017) Targeting effect of microRNA on CD133 and its impact analysis on proliferation and invasion of glioma cells. Genet Mol Res. 2017, 16(1).

8. Gao Y, Feng B, Han S, Lu L, Chen Y, Chu X, Wang R, Chen L (2016) MicroRNA-129 in Human Cancers: from Tumorigenesis to Clinical Treatment. Cell Physiol Biochem 2016; 39: 2186-2202

9. Gao Y, Feng B, Han S, Zhang K, Chen J, Li C, Wang R, Chen L (2016) The Roles of MicroRNA-141 in Human Cancers: From Diagnosis to Treatment. Cell Physiol Biochem 2016; 38: 427-448.

10. Farazi TA, Hoell JI, Morozov P, Tuschl T (2016) MicroRNAs in human cancer. Adv Exp Med Biol 2013;774: 1-20.

11. $\mathrm{Xu} \mathrm{R}$, Liu S, Chen H, Lao L (2016) MicroRNA-30a downregulation contributes to chemoresistance of osteosarcoma cells through activating Beclin-1-mediated autophagy. Oncol Rep 2016;35: 1757-1763.

12. Hidirov BN (2014) Selected works on mathematical modeling living systems regulatorika. Moscow-Ijevsk, 2014, 304 P. (in Russian). 